
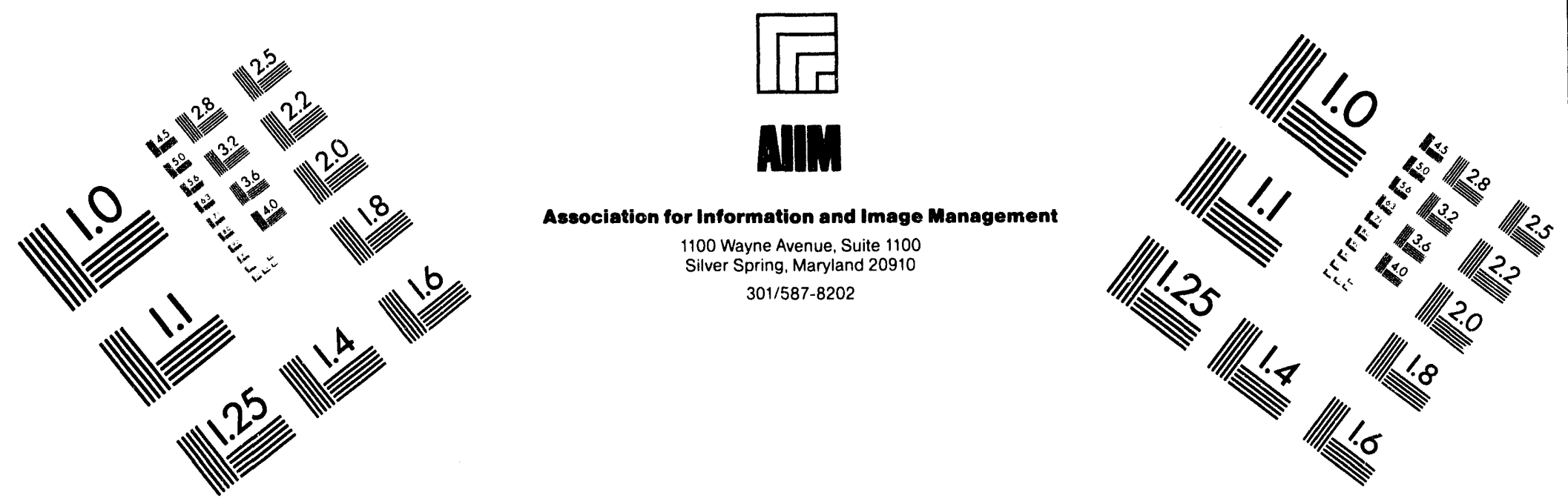

Centimeter

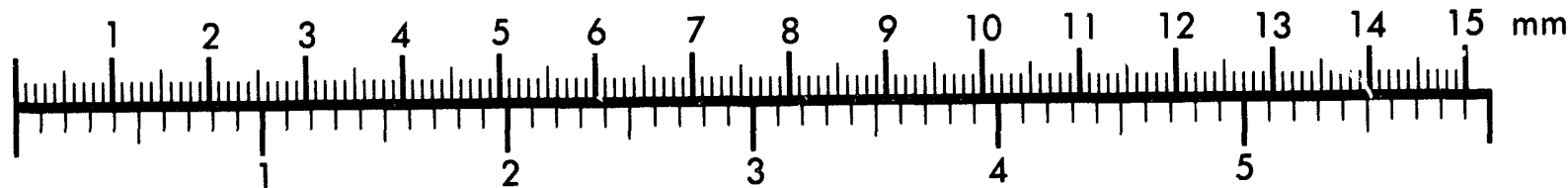

Inches
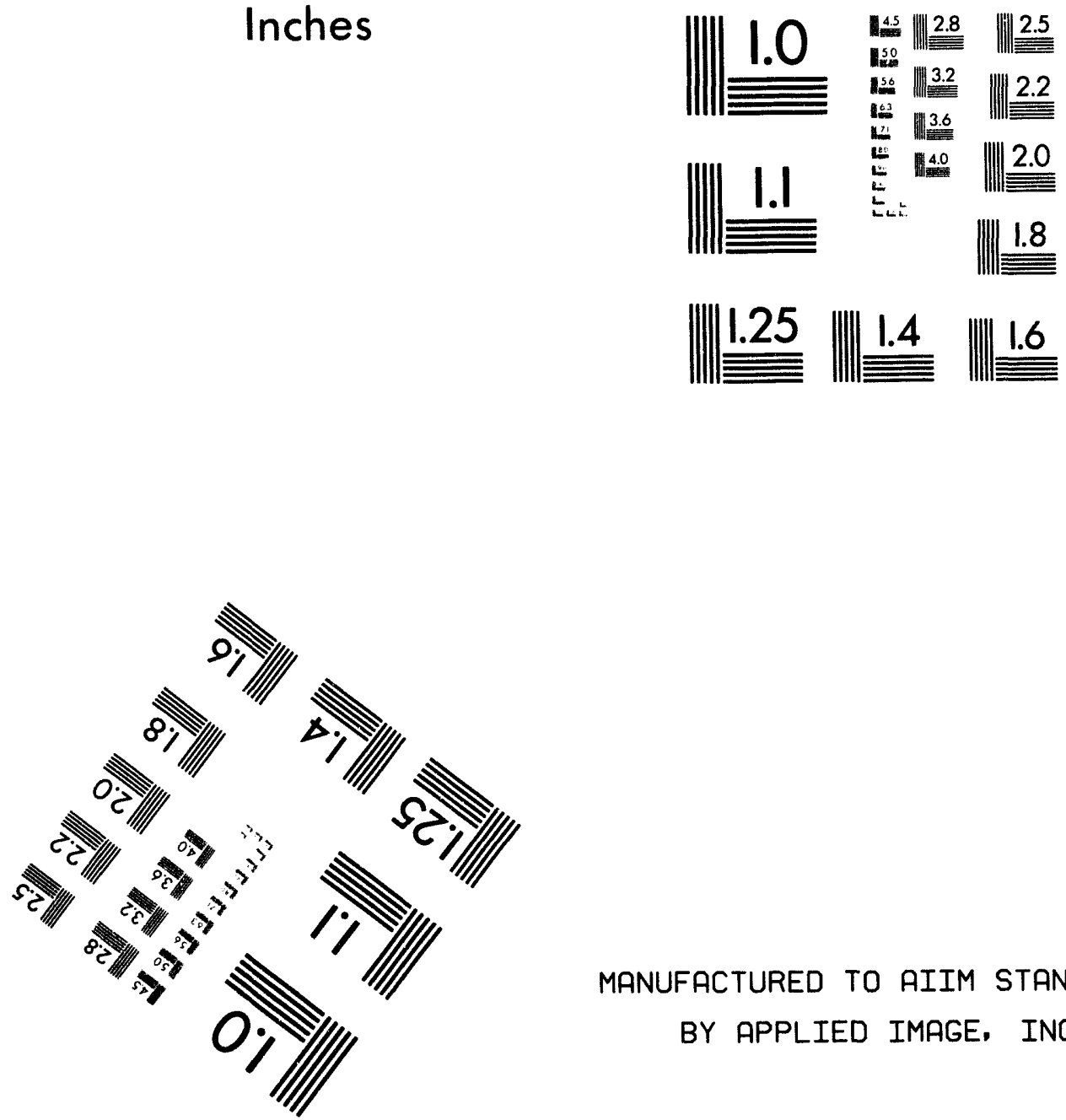

MANUFACTURED TO AIIM STANDARDS

BY APPLIED IMAGE, INC.

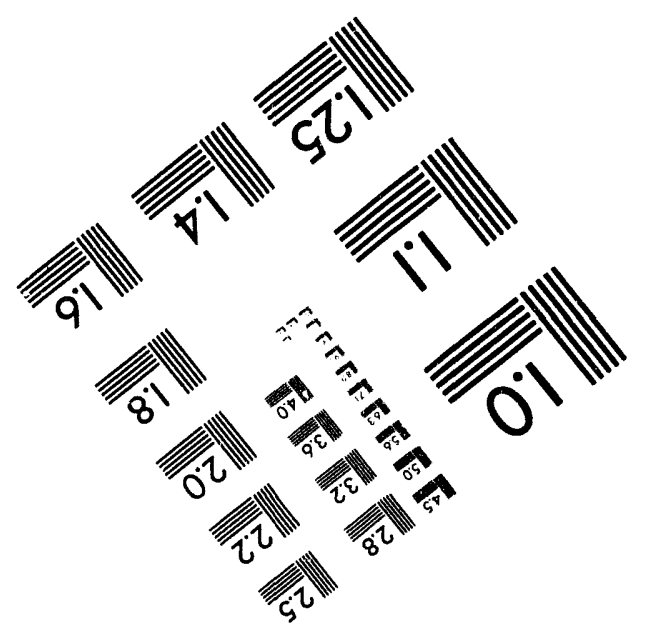



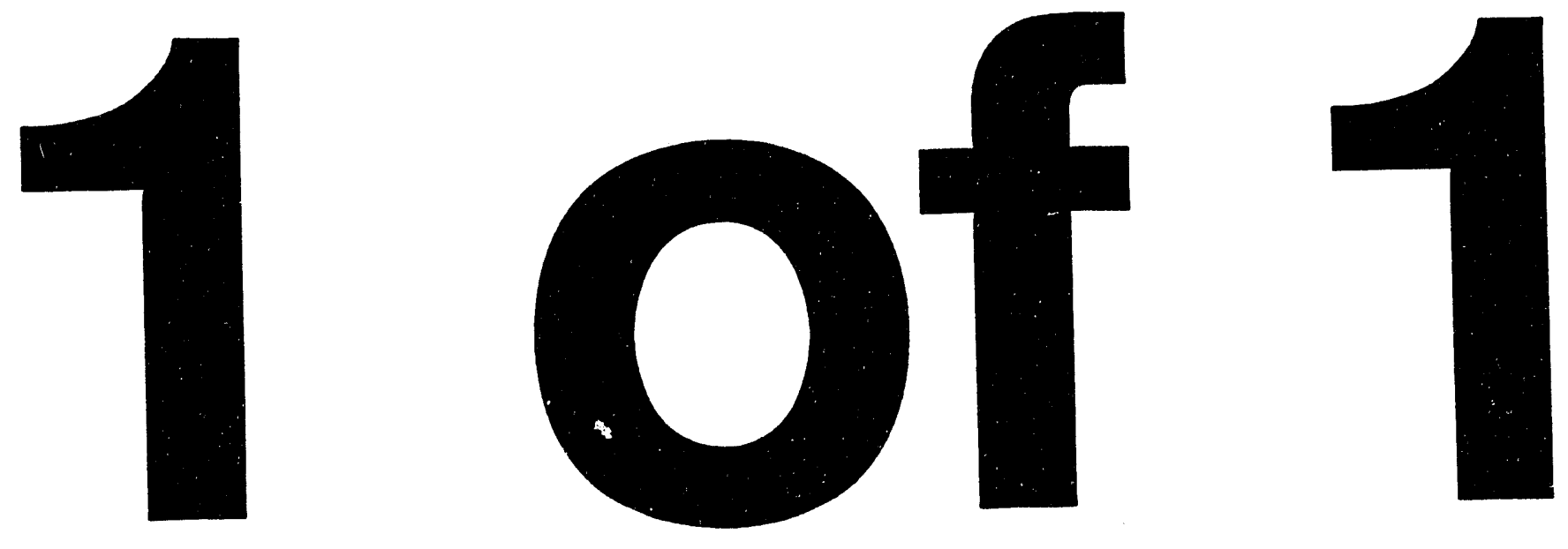


\title{
PROGRESS REPORT
}

\section{"Defects and Transport in Mixed Oxides"}

\section{DOE Grant No. DE-FGO2-88ER45357}

\author{
Rüdiger Dieckmann \\ Department of Materials Science and Engineering \\ Cornell University \\ Ithaca, NY 14853-1501 \\ (607) $255-4315$
}

\section{DISCLAIMER}

This report was prepared as an account of work sponsored by an agency of the United States Government. Neither the United States Government nor any agency thereof, nor any of their employees, makes any warranty, express or implied, or assumes any legal liability or responsibility for the accuracy, completeness, or usefulness of any information, apparatus, product, or process disclosed, or represents that its use would not infringe privately owned rights. Reference herein to any specific commercial product, process, or service by trade name, trademark, manufacturer, or otherwise does not necessarily constitute or imply its endorsement, recommendation, or favoring by the United States Government or any agency thereof. The views and opinions of authors expressed herein do not necessarily state or reflect those of the United States Government or any agency thereof.

September 30, 1993 


\section{INTRODUCTION}

The $\mathrm{Pl}$ of this research program came to Cornell University from Hannover (Germany) in July 1987. Beginning in Fall 1987 a new research group and new research facilities were built up at Cornell. The program "Defects and Transport in Mixed Oxides" was started in July 1988. The last progress report for this program was written on December 21, 1992 and submitted to DOE with the continuation proposal for the period 07/01/93-06/30/94.

\section{PERSONNEL}

Currently, two students (Sanjeev Aggarwal and Fu-Hsing Lu) are supported within this DOE sponsored research program. Until recently, a third student (Ramesh Subramanian), now supported by ONR, devoted some time to the completion of the thermodynamic studies he carried out while supported in this program. Furthermore, another student (Steven Tinkler) was supported for one year until the end of Spring 1993 from this grant. Steven Tinkler has worked on the cation tracer diffusion in $(\mathrm{Co}, \mathrm{Fe})_{3-\delta} \mathrm{O}_{4}$ mixed spinels (jointly with Fu-Hsing $\mathrm{Lu}$ ) and on the cation tracer diffusion and elecirical conduction in $(\mathrm{Co}, \mathrm{Fe})_{1-\Delta} \mathrm{O}$ mixed oxides.

\section{COLLABORATIONS}

During this research program some very important, cooperative investigations have been established which have been explained in detail in the previous report. All these collaborations are continuing. The collaborators and their affiliations are listed below as well as news from these collaborations:

- Dr. Carol Nichols, Department of Materials Science and Engineering, Cornell University: A first joint manuscript dealing with Monte Carlo simulations of the cation diffusion via vacancies in spinels has been completed and is currently under review (see \# 1 in the third part of Section 6.1.).

- Dr. Klaus-Dieter Becker, Institute for Physical Chemistry and Electrochemistry, University of Hannover, Germany, professor: First results from in-situ Mössbauer spectroscopy measurements on the cation distribution in the spinel solid solution $(\mathrm{Fe}, \mathrm{Mn})_{3} \mathrm{O}_{4}$ at $1200^{\circ} \mathrm{C}$ have become available. Their detailed interpretation, however, has still some problems. Furthermore, in collaboration with Dr. A. Chadwick (England) Dr. Becker has recently performed first in-situ EXAFS measurements on the cation distribution in $(\mathrm{Co}, \mathrm{Fe}, \mathrm{Mn})_{3} \mathrm{O}_{4}$ spinel solid solutions at Daresbury (England). It is not yet clear whether the data resulting from this study will provide unequivocal cation distribution information for the interpretation of the diffusion and nonstoichiometry results from our program.

- Dr. Alan Chadwick, University Chemical Laboratory, University of Kent, Canterbury, UK, professor: Dr. Chadwick is involved in the high temperature EXAFS cation 
distribution stı dies mentioned before.

- Dr. Arthur Pelton, Ecole Polytechnique, Montreal, Canada, professor, doctoral degree in metallurgical engineering: A joint manuscript dealing with the modelling of phase equilibria in the system Co-Fe-Mn-O has recently been submitted for publication. From this study some information has become available on the cation distribution in $(\mathrm{Co}, \mathrm{Fe}, \mathrm{Mn})_{3-\delta} \mathrm{O}_{4}$ at $1200{ }^{\circ} \mathrm{C}$, see \# 3 in the third part of Section 6.1.

- Dr. Peter Franke, Max-Planck-Institute for Steel Research, Düsseldorf, Germany, senior research associate, doctoral degree in physical chemistry: Dr. Franke is still working on Madelung energy calculations in spinel solid solutions which take into account point defects. These calculations are hoped to provide information on the composition dependence of equilibrium constants for point defect formation reactions and on the distribution of cations and defects among different coordinations. Dr. Franke has helped us in the past year as an "internal" reviewer for our manuscripts on the thermodynamics of $(\mathrm{Fe}, \mathrm{Mn})_{1-\Delta} \mathrm{O}$ and $(\mathrm{Fe}, \mathrm{Co})_{1-\Delta} \mathrm{O}$ solid solutions at $1200^{\circ} \mathrm{C}$ (see \# 1 and 2 in the second part of Section 6.1.).

- Dr. Robert Freer, Manchester Materials Science Centre, University of Manchester and UMIST, Manchester, UK, senior lecturer, doctoral degree in physics: Information has been exchanged and several topics of our and Freer's research have been discussed via E-mail and in person. We have an active NATO travel grant to partially support this collaboration. The PI of this program will visit Manchester in October to discuss the further collaboration. The UK part involves defect calculations and oxygen diffusion measurements and is complementary to our work.

\section{LABORATORY INSTALLATION}

During the past year we have completed the installation of a set-up for high temperature impedance spectroscopy in our lab which we are now beginning to use for electrical conductivity measurements in this program.

\section{PERFORMED RESEARCH}

In the following, only results obtained after the progress report of December 21, 1992 are reported. Significant progress has been made since then in the following areas: (i) nonstoichiometry of rock salt structure oxide solid solutions, (ii) cation tracer diffusion in oxide solid solutions of the types $(\mathrm{Co}, \mathrm{Mn})_{3-\delta} \mathrm{O}_{4}$ and $(\mathrm{Co}, \mathrm{Fe})_{1-\Delta} \mathrm{O}$, (iii) electrical conductivity studies in the solid solution $(\mathrm{Co}, \mathrm{Fe})_{1-\Delta} \mathrm{O}$, (iv) Monte-Carlo simulation of the cation diffusion in spinel solid solutions, $(v)$ thermodynamic modelling of the ternary phase diagram of the system Co-Fe-Mn-O and of the boundary systems Co-Fe-O and Fe-Mn-O at $1200^{\circ} \mathrm{C}$, and also (vi) interdiffusion studies in spinel solid solutions. 


\subsection{Nonstoichiometry in Quasi-Binary Rock Salt Structure Oxide Solid Solutions}

The deviation from stoichiometry in $\left(\mathrm{Co}_{x} \mathrm{Fe}_{1-x}\right)_{1-\Delta} \mathrm{O}$ quasi-binary spinel solid solutions has been measured thermogravimetrically at $1200^{\circ} \mathrm{C}$ as a function of oxygen activity and cationic composition covering practically the entire stability range of this phase. The nonstoichiometry data obtained for $\left(\mathrm{Co}_{x} \mathrm{Fe}_{1-x}\right)_{1-\Delta} \mathrm{O}$ are shown in Fig. 1 and summarized by solid lines. All lines have been derived by modelling the experimental data with a simple thermodynamic model which does not consider any specific defects because of the uncertainties existing with regard to the specific type of the occurring defects and the unsolved problems in an appro-

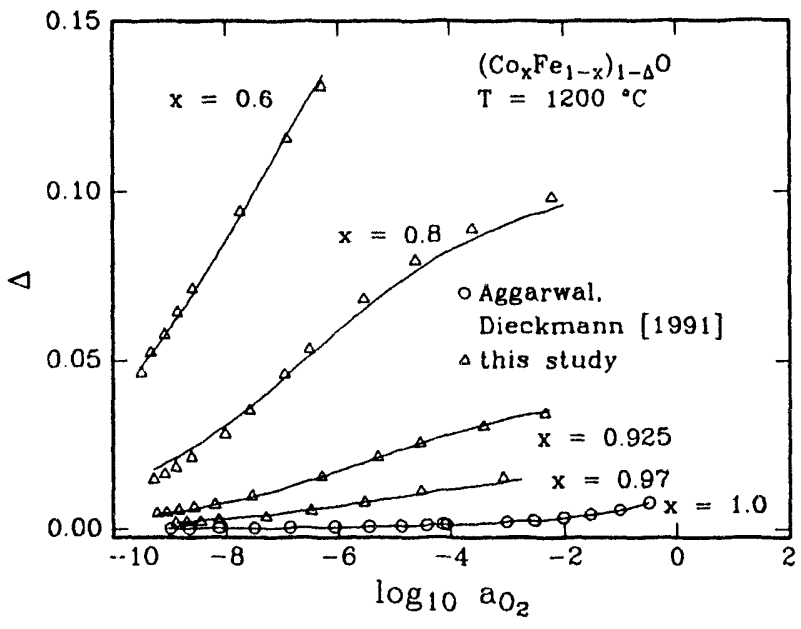

Figure 1: Oxygen activity dependence of the deviation from stoichiometry in the oxide solid solution $\left(\mathrm{Co}_{x} \mathrm{Fe}_{1-x}\right)_{1-\Delta} \mathrm{O}$ at $1200^{\circ} \mathrm{C}$.

priate thermodynamic treatment of highly concentrated solutions of charged defects in solids. The model basically attributes the changes of $\Delta$ with oxygen activity to a small contribution from $\mathrm{CoO}$ in the oxide solid solution and a large one caused by oxidizing $\mathrm{FeO}$ to $\mathrm{FeO}_{1.5}$ in the oxide solid solution. As the lines shown in Fig. 1 demonstrate, such a model very well describes the oxygen activity dependencies of $\Delta$ at different cationic compositions. The predominant defects are very likely isolated cation vacancies at small $\Delta$-values and "bound" cation vacancies at large $\Delta$-values. These "bound" vacancies may be arranged in defect clusters, possibly including an interstitial cation. The experimental data obtained in this study compare reasonably well with some of the results from earlier studies by Aukrust and Muan [1964] and by Raeder et al. [1984]. More details about the thermodynamic modelling of the nonstoichiometry data are reported in a paper which has been accepted for publication in Journal of Physics and Chemistry of Solids (\# 3 of accepted, project-related papers in Section 6.1.).

\subsection{Cation Tracer Diffusion in Oxide Solid Solutions}

Measurements of cation tracer diffusion coefficients of $\mathrm{Co}, \mathrm{Fe}$ and $\mathrm{Mn}$ ions in the spinel solid solution $\left(\mathrm{Co}_{x} \mathrm{Mn}_{1-x}\right)_{3-\delta} \mathrm{O}_{4}$ at $1200^{\circ} \mathrm{C}$ as a function of oxygen activity and cationic composition have been completed. Furthermore, analogous measurements have been initiated and completed for $\left(\mathrm{Co}_{x} \mathrm{Fe}_{1-x}\right)_{1-\Delta} \mathrm{O}$ quasi-binary oxide solid solutions at $1200^{\circ} \mathrm{C}$. As in previous tracer diffusion studies conducted in this research program, the methods used allow for the simultaneous measurement of cation tracer diffusion coefficients of $\mathrm{Co}-60, \mathrm{Fe}-59$, and $\mathrm{Mn}-54$. 
For the spinel solid solution $\left(\mathrm{Co}_{x} \mathrm{Mn}_{1-x}\right)_{3-\delta} \mathrm{O}_{4}$ at $1200^{\circ} \mathrm{C}$, in principle, all plots reporting cation tracer diffusion coefficients as a function of oxygen activity by using logarithmic scales show Vshaped curves, see Fig. 2. The observed oxygen activity dependencies for spinels indicate that the high temperature cation diffusion is governed by cation vacancies at high oxygen activities and by cation interstitials at low oxygen activities. By combining nonstoichiometry and diffusion data, mean mobilities of cations diffusing via vacancies and interstitials have been derived. These mobilities show a complex composition dependence. This is attri-

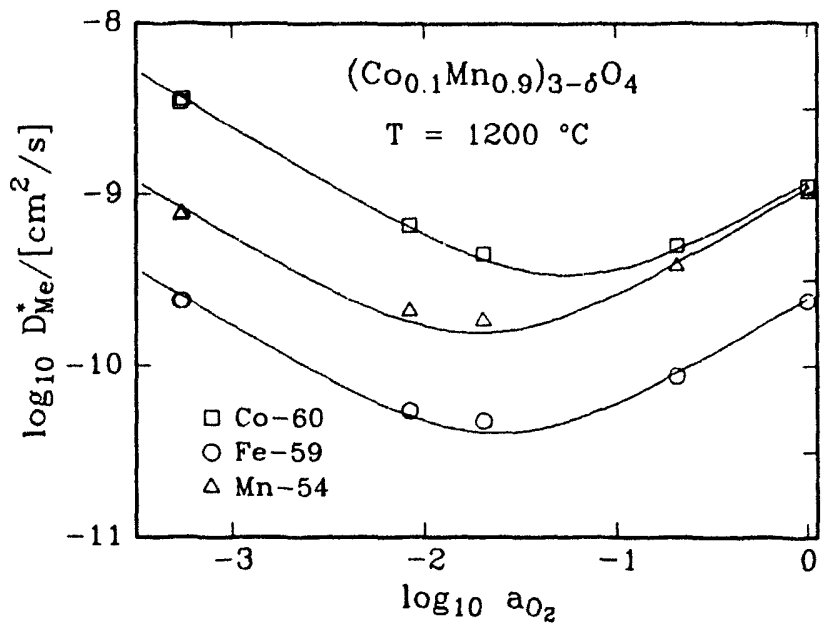

Figure 2: Oxygen activity dependence of cation tracer diffusion coefficients in $\left(\mathrm{Co}_{0.1} \mathrm{Mn}_{0.8}\right)_{3-8} \mathrm{O}_{4}$ at $1200^{\circ} \mathrm{C}$.

buted, to a large extent, to the change of the cation distribution with cationic composition. With regard to the diffusion mechanisms the results obtained suggest that these are the same for all compositions investigated: a vacancy diffusion mechanism prevails at high oxygen activities and an interstitialcy mechanism (= indirect interstitial mechanism) at low oxygen activities. More details are reported in a manuscript recently accepted by Solid State Ionics (\# 4 of the papers listed in the second part of Section 6.1.).

For the diffusion of $\mathrm{Co}, \mathrm{Fe}$ and $\mathrm{Mn}$ in $\left(\mathrm{Co}_{x} \mathrm{Fe}_{1-\mathrm{x}}\right)_{1-\Delta} \mathrm{O}$ at $1200^{\circ} \mathrm{C}$ very complex oxygen activity dependencies have been experimentally observed. As an example, the oxygen activity dependencies of the iron tracer diffusion data measured for different cationic compositions are shown in Fig. 3. The oxygen activity dependence observed for the iron tracer diffusion could be attributed to $\mathrm{Fe}^{2+}$ and $\mathrm{Fe}^{3+}$ diffusing at different rates via cation vacancies. However, because oxygen activity dependencies similar to those shown in Fig. 3 have been observed for the cobalt

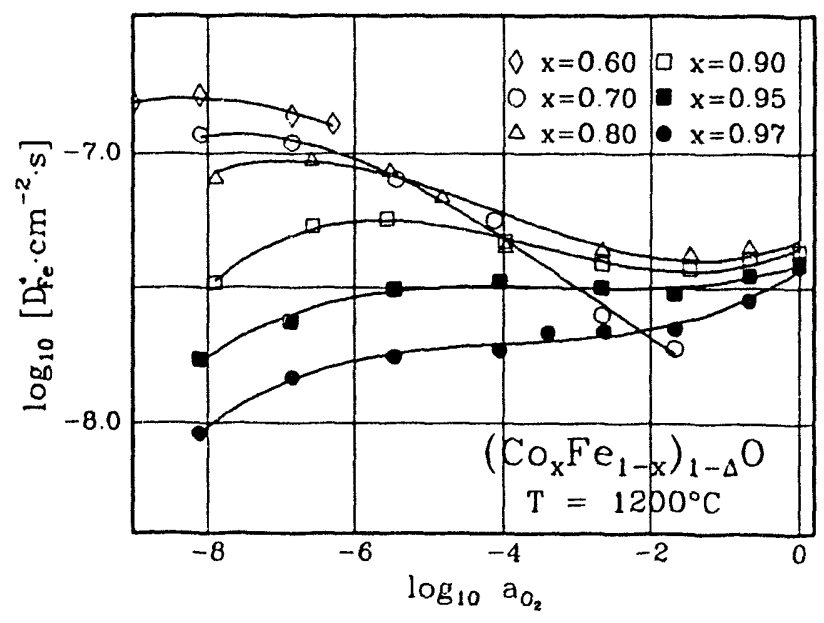

Figure 3: Experimental results for the tracer diffusion of $\mathrm{Fe}-59$ in $\left(\mathrm{CO}_{x} \mathrm{Fe}_{1-x}\right)_{1-\Delta} \mathrm{O}$ at $1200^{\circ} \mathrm{C}$. tracer diffusion (and also for the manganese tracer diffusion), such an explanation cannot hold. All Co-ions essentially are $\mathrm{Co}^{2+}$ ions. Therefore we have concluded that the observed oxygen activity dependencies must be attributed to a change in the type of defect participating in the cation tracer diffusion with oxygen activity. The observed oxygen activity dependencies can be explained quali- 
tatively if isolated cation vacancies prevail at small $\Delta$-values and "bound" vacancies, i.e. vacancies occurring in associates or clusters are predominant at high oxygen activities. A very simple model to estimate qualitatively the fractions of vacancies that are isolated and "bound" has been developed and used to make an estimate for $\left(\mathrm{Co}_{0.8} \mathrm{Fe}_{0.2}\right)_{1-\Delta} \mathrm{O}$ at $1200{ }^{\circ} \mathrm{C}$. The results obtained are shown in Fig. 4. It is worth noting that in reality the curves shown for isolated and "bound" vacancies will run slightly differently (and have no corners). Based on a defect population as shown in Fig. 4 the complex oxygen activity dependencies of the cation tracer diffusion data, especially the minima occurring at $x \sim 0.8$, can be explained by assuming that the mobilities of cations by isolated and "bound" vacancies are different. A quantitative analysis cannot be performed at present because of uncertainties involved. Details about the experiments and the modelling carried out are reported in a manuscript which has been submitted to Journal of Physics and Chemistry of Solids and is under review now (\# 2 in the third part of Section 6.1.).

\subsection{Electrical Conductivity Studies in the Solid Solution $(\mathrm{Co}, \mathrm{Fe})_{1-\Delta} \mathrm{O}$}

The oxygen activity dependence of the electrical conductivity of $\left(\mathrm{Co}_{x} \mathrm{Fe}_{1-x}\right)_{1-\Delta} \mathrm{O}$ mixed oxides with different composition $x$ has been measured at $1200^{\circ} \mathrm{C}$. A remarkable feature, especially well pronounced at $x=0.7$ and $x=0.8$ is the maximum of $\sigma$ occurring at lower oxygen activities, as shown in Fig. 5. How can this be explained? In the literature there is general agreement that the electrical conduction in $\mathrm{Fe}_{1-\Delta} \mathrm{O}$, one of the endmembers of the solid solution $\left(\mathrm{Co}_{x} \mathrm{Fe}_{1-\mathrm{x}}\right)_{1-\Delta} \mathrm{O}$, occurs by a small polaron hopping mechanism, i.e. by an electron exchange between $\mathrm{Fe}^{2+}$ and $\mathrm{Fe}^{3+}$ ions. If the exchange frequency is independent from composition, the conductivity then is proportional to the product between the concentrations of $\mathrm{Fe}^{2+}$ and

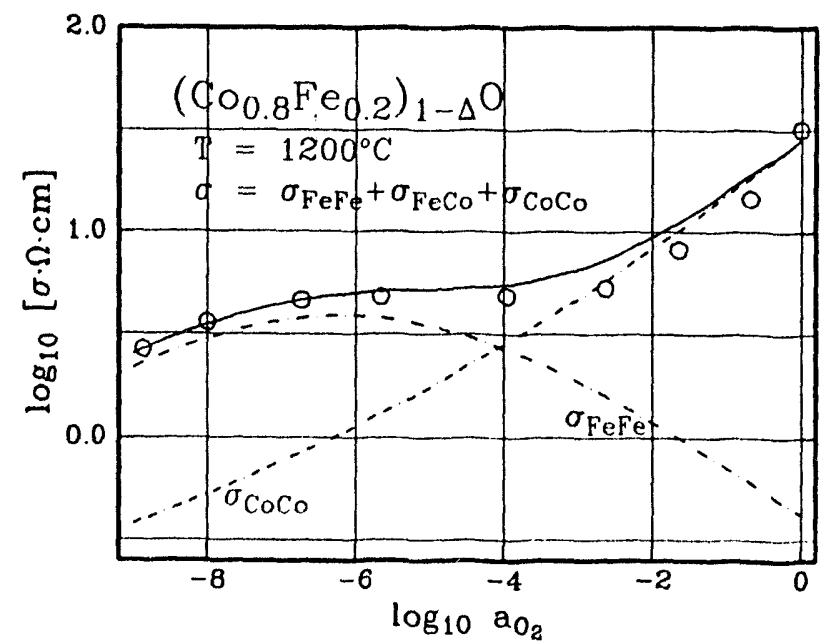

Figure 5: Electrical conductivity data measured in $\left(\mathrm{Co}_{0.8} \mathrm{Fe}_{0.2}\right)_{1-\Delta} \mathrm{O}$ at $1200^{\circ} \mathrm{C}$ in comparison with a line obtained by fitting these data to a model. 
$\mathrm{Fe}^{3+}$ ions. The nature of the electrical conduction mechanism in the other solid solution endmember, $\mathrm{Co}_{1-\Delta} \mathrm{O}$, is not unanimously agreed upon. The conductivity of oxides of the solid solution $\left(\mathrm{Co}_{x} \mathrm{Fe}_{1-x}\right)_{1-\Delta} \mathrm{O}$ can be very well described by assuming that the overall conductivity consists of contributions of $\mathrm{Co}_{1-\Delta} \mathrm{O}$ and of $\mathrm{Fe}_{1--\Delta} \mathrm{O}$ present in the solid solution. Fits show that the electron exchange between chemically different ions does not significantly contribute to the overall conduction. By assuming that the contribution of $\mathrm{Co}_{1-\Delta} \mathrm{O}$ to the electrical conduction, $\sigma_{\mathrm{CoO}}$, is equal to $\mathrm{x} \cdot \sigma_{\mathrm{CoO}}^{\circ}$ with $\sigma_{\mathrm{CoO}}^{\circ}$ as the electrical conductivity of pure cobaltous oxide, determining the concentrations of $\mathrm{Fe}^{2+}$ and of $\mathrm{Fe}^{3+}$ ions from the fit performed for the experimental data for the deviation from stoichiometry in $\left(\mathrm{Co}_{\mathrm{x}} \mathrm{Fe}_{1-x}\right)_{1-\Delta} \mathrm{O}$ and using a mobility term as the only (composition-dependent) fitting parameter, the experimentally observed oxygen activity dependencies of the measured electrical conductivities can be very well described as demonstrated by the solid line shown in Fig. 5. The mobility term of the electron exchange between $\mathrm{Fe}^{2+}$ and $\mathrm{Fe}^{3+}$ ions decreases strongly with decreasing iron content. More details about the experimental results and the modelling performed are reported in a manuscript submitted to Journal of Physics and Chemistry of Solids (\# 2 in the third part of Section 6.1.). This manuscript is currently under review.

\subsection{Monte Carlo Simulation in Mixed Spinels}

Since the last progress report submitted, the developed program for the simulation of the diffusion of cations in mixed spinels of the type $\left(A_{1-x} B_{x}\right)_{3-\delta} O_{4}$ by cation vacancies has been used to determine the values of correlation factors for such cases in which only one type of exchange jump occurs, i.e. (i) only jumps on the octahedral sublattice, (ii) only jumps on the tetrahedral sublattice, and (iii) only exchange jumps between these two sublattices. The ratios of the frequencies at which the chemically different cations exchange their sites with cation vacancies have been systematically varied, as well as the cationic compositions of the spinels

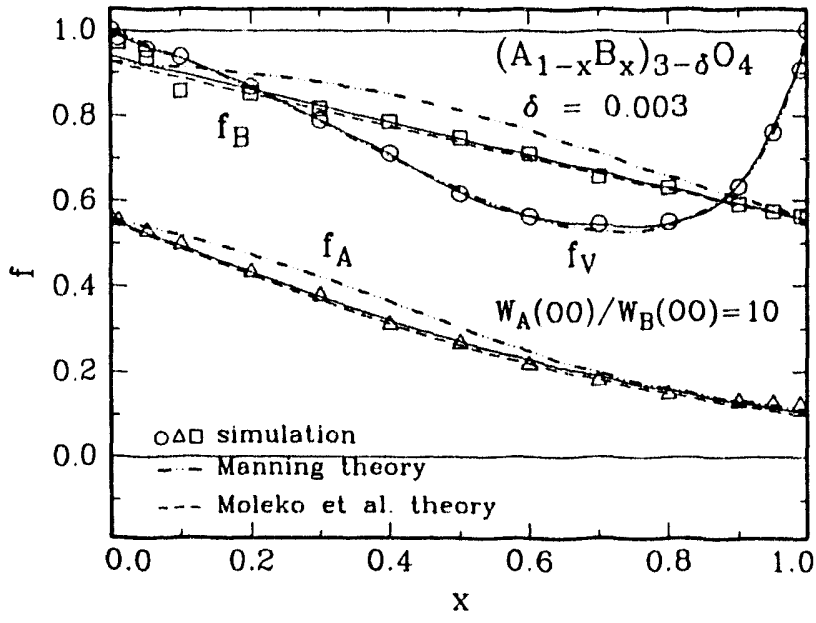

Figure 6: Vaives of correlation factors for the diffusion of cations via vacancies and of cation vacancies in $\left(A_{x} B_{-x}\right)_{3} O_{4}$ as a function of the composition, $x$. considered. Some results for case (i) are shown in Fig. 6. As expected, the correlation factor of the faster moving species, $A$, decreases with increasing content of $B$, i.e. the motion of $A$ is increasingly slowed down by correlation effects. The maximum correlation influence on the diffusion of cation vacancies occurs at about $x=0.7$. In the cases (i) and (ii) the results for $f_{A}$ and $f_{B}$ obtained can be compared with values calculated based on Manning's theory (Manning 
[1968]) and on Moleko et al.'s theory (Moleko et al. [1989]). As follows from Fig. 6, a better agreement is obtained with the results obtained by using Moleko et al.'s theory. The vacancy correlation factors obtained based on Manning's theory compare well with those resulting from our Monte Carlo simulations. Similar comparisons hold for the cation diffusion via vacancies exclusively on tetrahedrally coordinated lattice sites. No comparisons are possible for case (iii) because none of the theories mentioned above can be applied here due to the exclusion of lattice sites of one type of coordination in the case of exchange jumps between different sublattices only. The maximum correlation in the vacancy diffusion occurs here at $x \sim 0.4$. More details about the simulations performed and their results are reported in a manuscript submitted to Journal of Applied Physics (\# 1 in the third part of Section 6.1.). The revised manuscript is currently under review. Currently, we perform Monte Carlo simulations for the diffusion of cations via vacancies in mixed spinels of the type $\left(\mathrm{A}_{1-x} \mathrm{~B}_{\mathrm{x}}\right)_{3-\delta} \mathrm{O}_{4}$ for cases in which different types of jumps occur simultaneously.

\subsection{Thermodynamic Modelling of Phase Equilibria in the System Co-Fe-Mn-O}

Since the last progress report we have completed our thermodynamic modelling of phase stabilities in the system Co-Fe-Mn-O and its boundary systems Co-Fe-O and $\mathrm{Fe}-\mathrm{Mn}-\mathrm{O}$ at $1200^{\circ} \mathrm{C}$, partially based on experimental data resulting from this program (see earlier reports).

The description obtained for the equilibrium between $(\mathrm{Fe}, \mathrm{Mn})_{3-\delta} \mathrm{O}_{4}$ and $(\mathrm{F} \in, \mathrm{Mn})_{1-\Delta} \mathrm{O}$ at $1200^{\circ} \mathrm{C}$ from our thermodynamic calculations is shown in the phase diagram in Fig. 7. The effect of the nonstoichiometry of the rock-salt structure phase on its free energy was investigated in detail and taken into account accurately by using our recent experimental data on the nonstoichiometry of $(\mathrm{Fe}, \mathrm{Mn})_{1-\Delta} \mathrm{O}$ at $120{ }^{\circ} \mathrm{C}$. The free energy change due to the nonstoichiometry of the solid solution was found to be significantly different from that predicted by using certain simplifying assumptions previously employed to model the nonstoichiometry effect on the free energy of the rock-salt structure phase. This effect must be taken into account when phase equilibria between nonstoichiometric oxides are calculated,

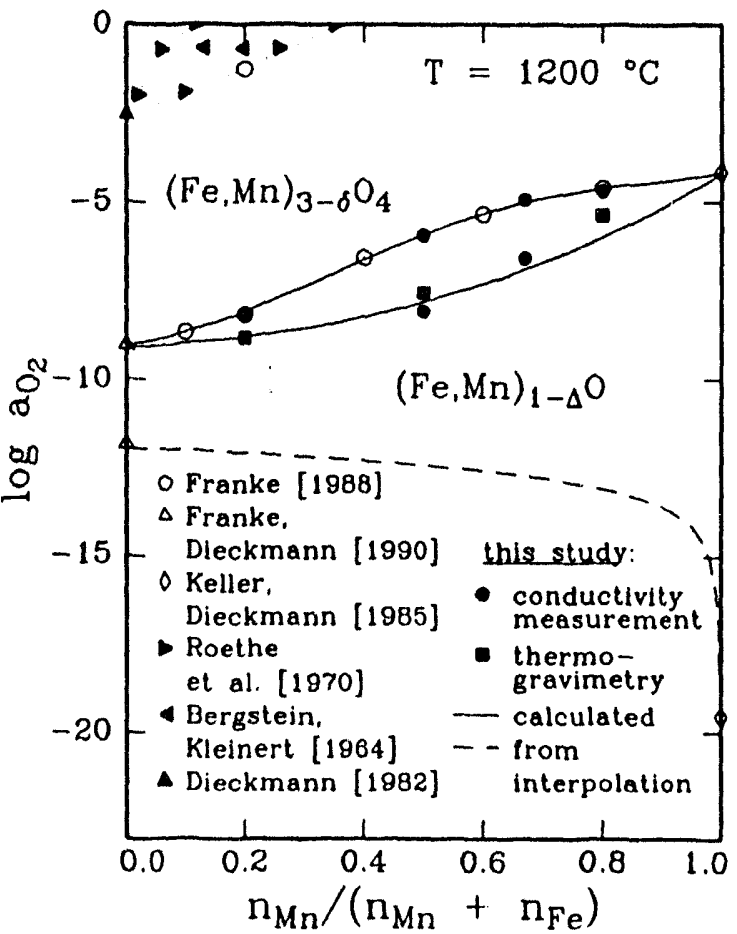

Figure 7: $\log a_{\mathrm{O}_{2}}$ vs composition phase diagram of the Fe-Mn-O system at $1200^{\circ} \mathrm{C}$. 
especially at high temperatures. Activities of $\mathrm{FeO}$ and of $\mathrm{MnO}$ in the solid solution $(\mathrm{Fe}, \mathrm{Mn})_{1-4} \mathrm{O}$ and of $\mathrm{FeO}_{4 / 3}$ and of $\mathrm{MnO}_{4 / 3}$ in $(\mathrm{Fe}, \mathrm{Mn})_{3-\delta} \mathrm{O}_{4}$ have also been calculated as a function of the cationic composition and in the case of the solid solution $(\mathrm{Fe}, \mathrm{Mn})_{1-\Delta} \mathrm{O}$ also as a function of the oxygen activity. The details of the calculations have been summarized in a manuscript accepted for publication in Journal of Physics and Chemistry of Solids (\# 1 of the accepted papers listed in Section 6.1.).

As mentioned before, thermogravimetric measurements of $\Delta$ in $\left(\mathrm{Fe}_{\mathrm{x}} \mathrm{Co}_{1-\mathrm{x}}\right)_{1-\Delta} \mathrm{O}$ at $1200^{\circ} \mathrm{C}$ have been performed during the past year. The results from these measurements have been used as input parameters for the modelling of the phase stabilities in the Co-Fe-O system. As in the case of the $\mathrm{Fe}-\mathrm{Mn}-\mathrm{O}$ system it has been found that it is very critical for the calculation that the deviations from stoichiometry in the rock salt structure phase are accurately accounted for. The solid line shown in Fig. 8 results from the calculations performed and very well describes most of the experimental phase stability data available from the literature. Data for the activities of $\mathrm{FeO}$ and $\mathrm{CoO}$ in $(\mathrm{Co}, \mathrm{Fe})_{1-\Delta} \mathrm{O}$ and of $\mathrm{FeO}_{4 / 3}$ and $\mathrm{Co}_{4 / 3}$ in

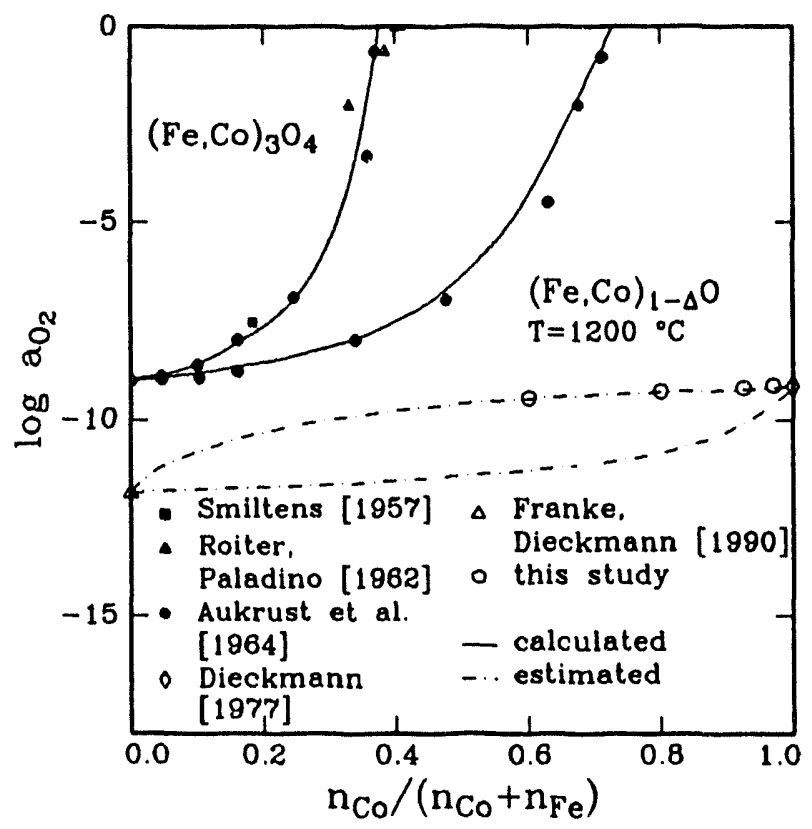

Figure 8: $\log \mathrm{a}_{\mathrm{O}_{2}}$ vs composition phase diagram of the Fe-Co-O system at $1200^{\circ} \mathrm{C}$. $(\mathrm{Co}, \mathrm{Fe})_{3-\delta} \mathrm{O}_{4}$ as a function of the cationic composition have also been calculated. The component activities in $(\mathrm{Co}, \mathrm{Fe})_{1-\Delta} \mathrm{O}$ have also been determined as a function of the oxygen activity. Details of the calculations and their results are reported in a manuscript accepted for publication in Journal of Physics and Chemistry of Solids (\# 2 of the accepted papers listed in Section 6.1.).

The modelling of phase stabilities in the quasi-ternary system Co-Fe-Mn-O by using a socalled sublattice model for formulating the free energy of the spinel phase has also been completed. Site preference energies determine the concentrations of the different ions in different coordinations. The influence of the nonstoichiometry on free energies was taken into account as far as the available experimental data allow for the rock salt structure phase. With this approach, the equilibria between $(\mathrm{Co}, \mathrm{Fe})_{1-\Delta} \mathrm{O}$ and $(\mathrm{Co}, \mathrm{Fe})_{3-\delta} \mathrm{O}_{4}$, $(\mathrm{Fe}, \mathrm{Mn})_{1-\Delta} \mathrm{O}$ and $(\mathrm{Fe}, \mathrm{Mn})_{3-\delta} \mathrm{O}_{4}$, and $(\mathrm{Co}, \mathrm{Fe}, \mathrm{Mn})_{1-\Delta} \mathrm{O}$ and $(\mathrm{Co}, \mathrm{Fe}, \mathrm{Mn})_{3-\delta} \mathrm{O}_{4}$ at $1200{ }^{\circ} \mathrm{C}$ have been calculated by free energy minimization. As an example for the results obtained the two-phase field existing between $(\mathrm{Co}, \mathrm{Fe}, \mathrm{Mn})_{1-\Delta} \mathrm{O}$ and $(\mathrm{Co}, \mathrm{Fe}, \mathrm{Mn})_{3-\delta} \mathrm{O}_{4}$ at $1200^{\circ} \mathrm{C}$ and $\log a_{\mathrm{O}_{2}}=-4$ is shown in Fig. 9 in comparison with experimental data. The dashdotted lines shown are tie lines for the coexistence of oxide solid solutions of different 
cationic compositions. A manuscript summarizing the data has been submitted very recently to Journal of Physics and Chemistry of Solids (see \# 3 in the third part of Section 6.1.). As a result of the use of the sublattice model, cation distribution information is obtained for the spinel phase. Due to the lack of reliable experimental data on this subject it is currently not known, how good this information is. In the case of the boundary system $(\mathrm{Co}, \mathrm{Fe})_{3-\delta} \mathrm{O}_{4}$, the cation distribution obtained from the modelling is not far from that proposed by Erickson and Mason [1985] based on thermopower measurements by making certain, experimentally unproven assumptions. An example of a cation distribution information obtained from the modelling is given in Fig. 10. We hope that some of the calculated cation distributions can be experimentally verified through one of the collaborations discussed in Section 3 and then be used to further analyze our experimental data on the nonstoichiometry of and the cation diffusion in the spinel solit solutions investigats $y$ in this research program.

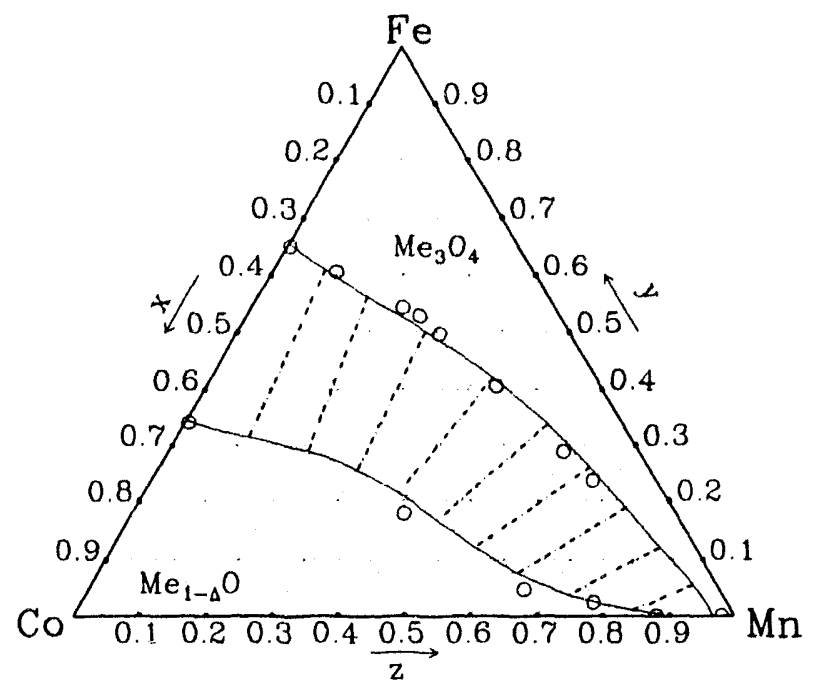

Figure 9: Two-phase region between spinel and rock salt structure phases in the system Co-Fe-Mn-O at $1200{ }^{\circ} \mathrm{C}$ and $\log \mathrm{a}_{\mathrm{O}_{2}}=-4$.

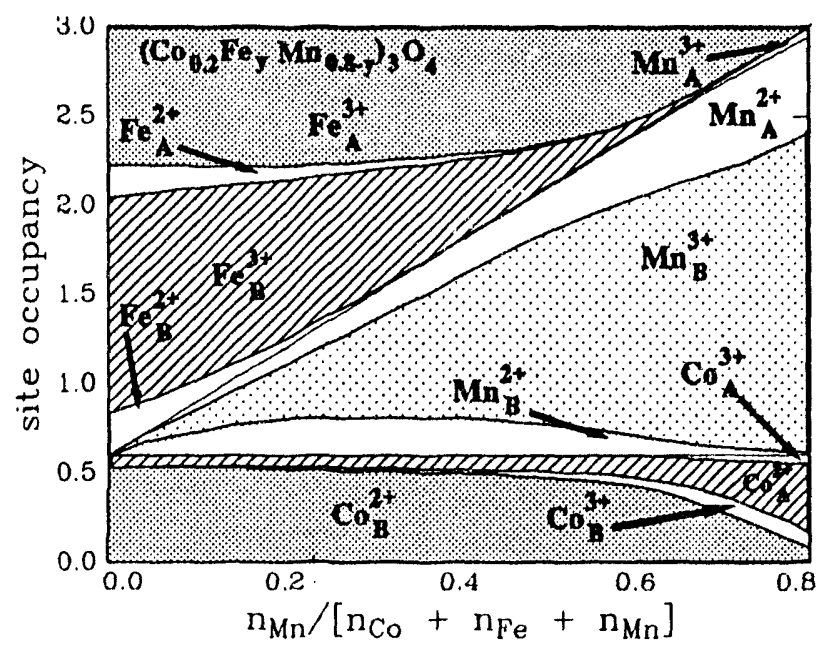

Figure 10: Cation distribution calculated for $\left(\mathrm{Co}_{0.2} \mathrm{Fe}_{\mathrm{y}} \mathrm{Mn}_{0.8-\mathrm{y}}\right.$ at $1200{ }^{\circ} \mathrm{C}$ as a function of the composition parameter $y$.

\subsection{Interdiffusion in Spinel Solid Solutions}

Recently, we have begun to perform some interdiffusion studies in spinel solid solutions within the system Co-Fe-Mn-O at $1200^{\circ} \mathrm{C}$. Since the cation tracer diffusion of all ions involved and the thermodynamics of the system considered are well known, the results from such experiments may be helpful fcr getting some experimental information on the diffusion correlation involved in the cation diffusion. The current status is that a couple of interdiffusion samples have been prepared and that the first interdiffusion profiles have been obtained. The detailed analysis of these profiles will begin soon. 


\subsection{Preparation of Impedance Measurements}

Since the last progress report, one of our existing controlled atmosphere furnaces has been modified to incorporate a short wire connection between instrument and sample holder. A special sample holder has been designed and built. First measurements are now underway, much later than anticipated.

As mentioned in an earlier progress report, in the Co-Fe-Mn-O system, if the conductivities of the pure rock salt structure and of the pure spinel phases are similar, a conductivity minimum is observed in the oxygen activity region where two phases coexist. This behavior will be further investigated by impedance measurements to determine if space charges at boundaries are responsible for the conductivity minimum.

Investigations of the influence of the grain size on the overall defect population will be attempted by using impedance spectroscopy. It is hoped that the results will be useful for better understanding the change of defect formation energies close to boundaries and will be used in conjunction with nonstoichiometry data obtained as a function of grain size.

\section{PUBLICATIONS}

\subsection{Recent Publications from this Project}

Since the last report, the following papers from this project have been published:

[1] "Point Defects and Cation Tracer Diffusion in (Co,Fe,Mn $)_{3-\delta} \mathrm{O}_{4}$ Spinels: II. Mixed Splnels $\left(\mathrm{Co}_{\mathrm{x}} \mathrm{Fe}_{\mathbf{z}} \mathrm{Mn}_{22}\right)_{3-\delta} \mathrm{O}_{4} "$

F.-H. Lu and R. Dieckmann

Solid State Ionics, 59 (1-2) [1993] 71-82.

[2] "Point Defects and Cation Tracer Diffusion in $(\mathrm{Co}, \mathrm{Fe}, \mathrm{Mn})_{3-\delta} \mathrm{O}_{4}$ Spinel Solld Solutions" F.-H. Lu and R. Dieckmann

Proceedings of the XII International Conference on Defects in Insulating Materials, Schloß Nordkirchen, Germany, August 16-22, 1992, O. Kanert and J.-M. Spaeth, Eds., World Scientific Publishing Co. Pte. Ltd., Singapore, [1993] Vol. 2, 982-984.

[3] "Point Defects and Cation Tracer Diffusion in $\left(\mathrm{Co}_{x} \mathrm{Fe}_{1-x}\right)_{3-\delta} \mathrm{O}_{4}$ Spinels"

F.-H. Lu, S. Tinkler and R. Dieckmann

Solid State lonics, 62 (1-2) [1993] 39-52.

[4] "Point Defects and Transport in Hematite $\left(\mathrm{Fe}_{2} \mathrm{O}_{3-\epsilon}\right)$ "

R. Dieckmann

Phil. Mag. A, 68 (4) [1993] 725-745.

The following manuscripts from this project have been accepted for publication:

[1] "Nonstoichlometry and Thermodynamics of (Fe,Mn) ${ }_{1-\Delta} \mathrm{O}$ Solld Solutions at $1200^{\circ} \mathrm{C}$ "

R. Subramanian and R. Dieckmann

J. Phys. Chem. Solids, (submitted 03/23/93, revised 05/24/93, accepted 06/11/93). 
[2]. "Thermodynamics of the Solid Solution $(\mathrm{Fe}, \mathrm{Co})_{1-1} \mathrm{O}$ at $1200^{\circ} \mathrm{C}$ "

R. Subramanian and R. Dieckmann

J. Phys. Chem. Solids, (submitted 06/03/93, revised 07/12/93, accepted 08/26/93).

[3] "Defects and Transport in the Solld Solution (Co,Fe) ${ }_{1-s} \mathrm{O}$ at $1200^{\circ} \mathrm{C}-\mathrm{I}$. Nonstolchlometry"

R. Subramanian, S. Tinkler and R. Dieckmann

J. Phys. Chem. Solids, (submitted 07/12/93, revised 08/11/93, accepted 08/26/93).

[4] "Point Defects and Cation Tracer Diffusion in $\left(\mathrm{Co}_{x} \mathrm{Mn} n_{1-x}\right)_{3-8} \mathrm{O}_{4}$ Spinels"

F.-H. Lu and R. Dieckmann

Solid State lonics, (submitted 09/08/93, accepted 09/24/93).

The following manuscripts from this project have been submitted for publication and are currently under review:

[1] "Monte Carlo Simulation of Cation Transport via Vacancles in Spinel Solid Solutions: I. One Type of Cation Exchange Prevalis"

F.-H. Lu, P. Franke, C.S. Nichols and R. Dieckmann

J. Appl. Phys., (submitted 05/24/93, revised 08/26/93).

[2] "Defects and Transport in the Solld Solution $(\mathrm{Co}, \mathrm{Fe})_{1-4} \mathrm{O}$ at $1200^{\circ} \mathrm{C}-\mathrm{II}$. Cation Tracer Diftuslon and Electrical Conductivity"

S. Tinkler, R. Subramanian and R. Dieckmann

J. Phys. Chem. Solids, (submitted 07/27/93).

[3] "Model Calculations of Phase Stabilities of Oxide Solld Solutions in the Co-Fe-Mn-O System at $1200^{\circ} \mathrm{C}$ "

R. Subramanian, R. Dieckmann, G. Eriksson and A. Pelton

J. Phys. Chem. Solids, (submitted 09/24/93).

\subsection{Other Publications}

Other publications which have appeared since the last report are:

[1] "The High Temperature Phase Dlagram of the System Cu-O in the Stability Reglon of Cuprous Oxide $\left(\mathrm{Cu}_{2-\delta} \mathrm{O}\right)^{n}$

J. Xue and R. Dieckmann

High Pressures - High Temperatures, 24 (3) [1992] 271-284.

[2] "Preparation of Uniformly CaO-Doped Zlrconia" J. Hill, M. Newhouse, J. Xue and R. Dieckmann Journal of Materials Synthesis and Processing, 1 (2) [1993] 101-109.

[3] "On the Use of Chemical Reequilibration to Determine True Diffusivity in CoO"

F. Morin and R. Dieckmann

J. Phys. Chem. Solids, 54 (1) [1993] 31-33.

[4] "In Situ Formation of Metal-Ceramic Microstructures, Including Metal-Ceramic Composites, Using Reduction Reactions"

E. Ustundag, R. Subramanian, R. Vaja, R. Dieckmann and S.L. Sass

Acta Metallurgica et Materialia, 41 (7) [1993] 2153-2161. 
[5] " Oxygen Content and Point Defects in Pure and Doped Zirconia $\left(\mathrm{ZrO}_{2}\right)$ " J. Xue and R. Dieckmann Proceedings of the XII International Conference on Defects in Insulating Materials, SchloB Nordkirchen, Germany, August 16-22, 1992, O. Kanert and J.-M. Spaeth, Eds., World Scientific Publishing Co. Pte. Ltd., Singapore, [1993] Vol. 2, 739-741.

[6] "Sol-Gel Synthesis of Chromlum-Doped Forsterite" D.G. Park. J.M. Burlitch, R.F. Geray, R. Dieckmann, D.B. Barber and C.R. Pollock Chem. Mater., 5 (4) [1993] 518-524.

Other manuscripts accepted for publication are:

[1] "Preparation of Olivines $\left(\mathrm{Fe}_{x} \mathrm{Mg}_{1-x}\right)_{2} \mathrm{SIO}$, by Sol-Gel Technique" T.-L Tsai and R. Dieckmann Journal of Materials Synthesis and Processing, (submitted 12/03/92, revised version 02/25/93, accepted 03/04/93).

[2] "In Situ Formation of Metal-Ceramic Microstructures by Partial Reduction Reactions" R. Subramanian, E. Ustundag, R. Dieckmann and S.L. Sass Proceedings of the Ceramic Matrix Composites Symposium, American Ceramic Society 95th Annual Meeting, April 18-22, 1993, Cincinnati, Ohio. U.S.A.

[3] "In Situ Formation of Metal-Ceramic Composites and Ductlle Phase Toughened Ceramics Using Partlal Reduction Reactions"

E. Ustundag, R. Subramanian, R. Dieckmann and S.L. Sass Proceedings Conference on Processing, Fabrication and Application of Advanced Composites, Long Beach, CA, August 9-11, 1993.

Other manuscripts which have been submitted for publication and are currently under review:

[1] "Oxidation of Aluminum Nitride Substrates"

D. Robinson and R. Dieckmann

J. Mater. Sci., (submitted 12/10/92).

[2] "Oxide Film Formation on Aluminum Nitride Substrates Covered with thin Aluminum Layers" D. Robinson and R. Dieckmann

J. Mater. Sci., (submitted 01/15/93).

[3] "Varlation of the Oxygen Content in Tetragonal, Calcium Oxide-Doped Zirconla" J. Xue and R. Dieckmann Solid State lonics, (submitted 04/05/93).

[4] "Growth of $\mathrm{Cr}^{4+}$-rich, Chromium-Doped Forsterite Single Crystals by the Floating Zone Method" M. Higuchi, R.F. Geray, R. Dieckmann, D.G. Park, J.M. Burlitch, D.B. Barber and C.R. Pollock J. Cryst. Growth, (submitted 08/06/93).

[5] "Formation of a New Aluminum Oxide with the Composition $\mathrm{AlO}_{2}$ by Interfacial Reaction between Pt and $\alpha \cdot \mathrm{Al}_{2} \mathrm{O}_{3}$

Y.-C. Lu, R. Dieckmann and S.L. Sass

Acta Metallurgica et Materialia, (submitted 08/20/93). 


\section{PRESENTATIONS}

Since December 21, 1992, there were eleven project-related presentations:

[1] "Defects and Transport in Non-Stolchiometric Oxides"

R. Dieckmann

Seminar, January 26, 1993, University of Pennsylvania, Philadelphia, U.S.A.

[2] "Defects and Transport in Mixed Oxides"

R. Dieckmann

DOE Program Review Meeting, March 10, 1993, Bethesda, MD, U.S.A.

[3] "Influence of Boundarles and Near-Boundary Reglons on the Oxygen Content of NonStoichlometric Oxides"

S. Agganwal, R. Dieckmann

95th Annual Meeting American Ceramic Society, April 18 - 22, 1993, Cincinnati, Ohio, U.S.A. (talk)

[4] "Monte Carlo Simulation of Cation Transport in Spinel Solld Solutions"

F.H. Lu, P. Franke, C.S. Nichois, R. Dieckmann

95th Annual Meeting American Ceramic Society, April 18 - 22, 1993, Cincinnati, Ohio, U.S.A. (talk)

[5] "Cation Tracer Diffusion and Electrical Conductivity in (Co,Fe) ${ }_{1-4} \mathrm{O}$ Mixed Oxides"

S. Tinkler, L. Gotshall, R. Dieckmann

95th Annual Meeting American Ceramic Society, April 18 - 22, 1993, Cincinnati, Ohio, U.S.A. (poster)

[6] "Cation Tracer Diffusion In $\left(\mathrm{Co}_{x} \mathrm{Mn}_{1-x}\right)_{3-\delta} \mathrm{O}_{4}$ Spinels"

F.-H. Lu, L. Gotshall, R. Dieckmann

95th Annual Meeting American Ceramic Society, April 18 - 22, 1993, Cincinnati, Ohio, U.S.A. (poster)

[7] "Point Defects and Cation Tracer Diffusion in (Co,Fe,Mn) $)_{3-\delta} \mathrm{O}_{4}$ Spinels"

F.H. Lu, R. Dieckmann

95th Annual Meeting American Ceramic Society, April 18 - 22, 1993, Cincinnati, Ohio, U.S.A. (talk)

[8] "Cation Transport and Solld State Reactions in the System Co-Fe-C"

S. Tinkler, R. Dieckmann

95th Annual Meeting American Ceramic Society, April 18 - 22, 1993, Cincinnati, Ohio, U.S.A. (talk)

[9] "Model Calculatlons of Phase Siabilitles of Mixed Oxides in the Co-Fe-Mn-O System at $1200^{\circ} \mathrm{C}$ " R. Subramanian, A.D. Pelton, G. Eriksson, R. Dieckmann

95th Annual Meeting American Ceramic Society, April 18 - 22, 1993, Cincinnati, Ohio, U.S.A. (poster)

[10] "Point Defects and Diffusion in Iron-Based Spinels and in Ollvines"

R. Dieckmann

AGU, MSA, GSA Joint Spring Meeting, May 24-28, 1993, Baltimore, MD, U.S.A.

[11] "Point Defects and Transport in Nonstolchiometric Oxides and Their Relationships to Solid State Reactions" (in German)

R. Dieckmann

Seminar Technische Universität Dresden, August 30, 1993, Dresden, Germany. 

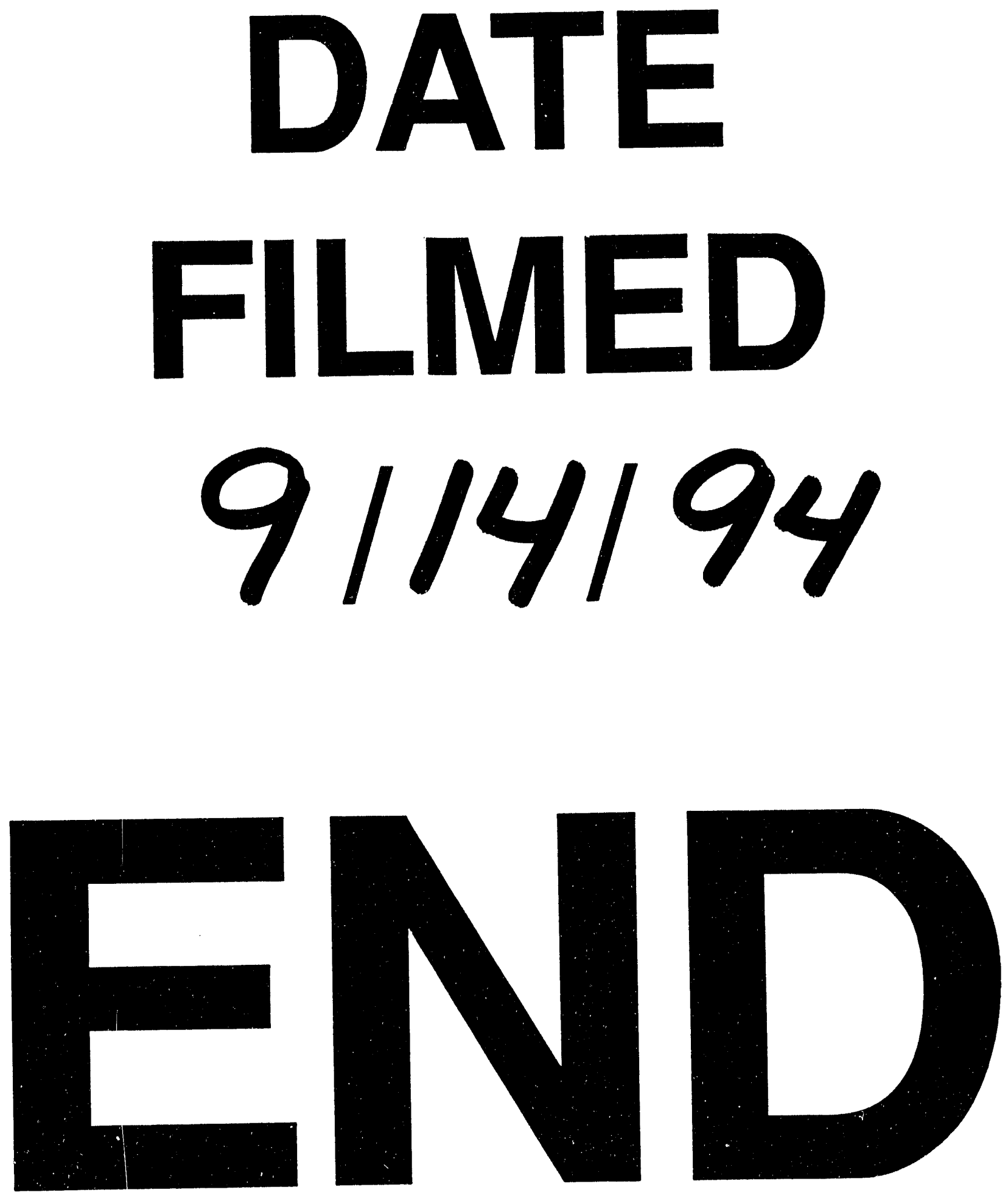


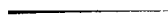

